1 A class I hydrophobin in Trichoderma virens influences plant-microbe interactions through enhancement of enzyme activity and MAMP recognition

3 James T. Taylor, Inna Krieger, Frankie K. Crutcher, Pierce Jamieson, Benjamin A. Hor-

4 witz, Michael V. Kolomiets, Charles M. Kenerley

5 Abstract

6 The filamentous fungus, Trichoderma virens, is a well-known mycoparasitic plant symbiont, val-

7 ued for its biocontrol capabilities. T. virens initiates a symbiotic relationship with a plant host

8 through the colonization of its roots. To achieve colonization, the fungus must communicate with

9 the host and evade its innate defenses. Hydrophobins from Trichoderma spp. have previously been

10 demonstrated to be involved in colonization of host roots. In this study, the class I hydrophobin,

11 HFB9A from $T$. virens was characterized for a potential role in root colonization. $\Delta \mathrm{hfb} 9 \mathrm{a}$ gene

12 deletion mutants colonized less than the wild-type strain, were unable to induce systemic resistance

13 against Colletotrichum graminicola, and showed a reduction in the activity of its cell wall degrad-

14 ing enzymes. The purified HFB9A protein was able to complement the enzyme activity of mutant

15 culture filtrates as well as enhance the activity of commercially sourced cellulase. When exoge-

16 nously applied to Arabidopsis plants, HFB9A protein induced phosphorylation of AtMAPK3/6,

17 suggesting that it functions as a microbe-associated molecular pattern.

\title{
18 Keywords
}

19 Trichoderma virens, Induced Systemic Resistance, Root Colonization, Hydrophobins, Plant-Mi-

20 crobe interactions

\section{Introduction}

The filamentous plant symbiotic fungus Trichoderma virens is recognized for its ability to

23 colonize plant roots and provide benefits to its hosts through the induction of systemic resistance, 
24 protection against fungal root pathogens, and growth promotion (Howell, 1987; Pieterse et al.,

25 2014; Saldajeno et al., 2014). During the colonization process, a large number of secreted fungal

26 proteins are involved in the subroutines of evading the plant defenses, initially penetrating roots,

27 and fungal growth within the root system by hyphal expansion (Djonović et al., 2006a; Crutcher

28 et al., 2015; Lamdan et al., 2015). In addition to fungal proteins that are secreted into intercellular

29 spaces, others localize to the outer cell wall of the fungus. Here, they can serve a wide variety of

30 functions such as receptors for specific stimuli, protect against antimicrobial compounds, and aid

31 in physical interactions including attachment to surfaces (Zampieri et al., 2010; Bignell, 2012;

32 Kim et al., 2016; Correia et al., 2017). Much effort has been extended to discover and understand

33 proteins involved in Trichoderma-plant interactions, with a major emphasis on small, secreted

34 cysteine-rich proteins hypothesized to function as effectors (Lamdan et al., 2015; Morán-Diez et

35 al., 2015; Guzmán-Guzmán et al., 2017; Ramírez-Valdespino et al., 2019). The best-known ex-

36 ample of this type of protein is SM1, which belongs to the cerato-platanin family and is required

37 for induced systemic resistance (ISR) mediated by T. virens (Djonović et al., 2006a; Djonović et

38 al., 2007). In sharp contrast, the role of other secreted protein families in Trichoderma-plant inter-

39 actions are much less understood. Of these families, hydrophobin proteins are of particular interest

40 due to their diverse suite of functions.

41 Hydrophobins are small cysteine-rich, secreted proteins that self-assemble at hydro-

42 philic/hydrophobic interfaces (Wösten, 2001) and are unique to fungi. They contain a conserved

43 motif of cysteine residues, which they may act as effectors involved in plant-fungal interactions,

44 similarly to other cysteine-rich proteins (Ruocco et al., 2015; Guzmán-Guzmán et al., 2017). As

45 secreted proteins, some hydrophobins cover the surface of spores of fungal pathogens, helping to

46 evade host defenses (Bayry et al., 2012). Others aid fungal morphogenesis by enabling hyphae to 
47 penetrate air/water interfaces (Wösten and de Vocht, 2000). The unique properties of hydro-

48 phobins are suited for a variety of applications in industrial and scientific techniques. The fusion

49 of a hydrophobin to a protein of interest can significantly boost the yield of the purified protein

50 (Joensuu et al., 2010; Mustalahti et al., 2013). Hydrophobins are also industrially used as emulsi-

51 fiers and agents to alter surface characteristics of substrates (Bayry et al., 2012). spacing between cysteines, and hydrophobicity patterns in the amino acid sequence (Wösten,

54 2001). Class II hydrophobins are more soluble than class I and have more conserved spacing be-

55 tween cysteines, whereas class I hydrophobins are very insoluble, requiring harsh acids to dissolve,

56 and can have highly variable cysteine spacing (Wösten and De Vocht, 2000; Wösten, 2001; Bayry

57 et al., 2012). Class I hydrophobins typically localize to the outer cell wall of fungal hyphae and/or

58 spores where they form monolayers or self-assemble into amyloid-like fibrils. This differs from

59 class II hydrophobins, which tend to be freely secreted into the environment. A limited number of

60 hydrophobins from Trichoderma species have been functionally characterized. A class I hydro-

61 phobin, TASHYD1 from T. asperellum, was found to aid in the attachment of conidia and hyphae

62 to roots for more efficient colonization of cucumber plants (Viterbo and Chet, 2006). A class II

63 hydrophobin, HYTLO1 from T. longibrachiatum, was shown to exhibit direct antifungal effects

64 and induce systemic resistance when applied to plant leaves (Ruocco et al., 2015). Additionally, a

65 class II hydrophobin from $T$. virens was demonstrated to have a role in root colonization and my-

66 coparasitism activity (Guzmán-Guzmán et al., 2017). Class I hydrophobins have been identified

67 in T. virens, but are fewer in number (three) than class II hydrophobins (eight), and no distinctive

68 role in plant interactions has been demonstrated (Seidl-Seiboth et al., 2011). One class I hydro-

69 phobin, HFB9A from $T$. virens, has been described that shares significant homology with 
70 TASHYD1 (Viterbo and Chet, 2006). Based on this homology and the typical characteristics of

71 hydrophobins, we hypothesized that HFB9A has a role in T. virens-plant interactions. In this study,

72 we demonstrate the function of the hfb9a gene in root colonization and induction of systemic re-

73 sistance in maize as well as the enhancement of enzyme activity on cell wall components.

\section{Materials and Methods}

\section{Bioinformatic analysis}

The protein sequences of selected proteins were subjected to a BLAST search of the NCBI

77 database for homologs. The resulting matches were aligned using CLUSTAL Omega software.

78 Additionally, the DNA sequence of the promoter and terminator regions of the hydrophobin were

79 queried through the Joint Genome Institute BLAST (https://mycocosm.jgi.doe.gov/pages/blast-

80 query.jsf?db=TriviGv29_8_2) search of the T. virens Gv29-8 genome.

\section{$81 \quad$ Strains and conditions}

82 The root pathogens, Pythium ultimum and Rhizoctonia solani, and the wild-type strain of

83 T. virens [Gv29-8] were maintained on potato dextrose agar (PDA, BD Difco ${ }^{\mathrm{TM}}$ ) at $27^{\circ} \mathrm{C}$. The

84 maize foliar pathogen Colletotrichum graminicola was maintained under an 14:10 light:dark light

85 regime at room temperature on PDA plates for sporulation. Chlamydospores of T. virens were

86 harvested from 14-day old cultures of T. virens grown in Fernbach flasks containing 1 L of molas-

87 ses medium ( $30 \mathrm{~g}$ molasses and $5 \mathrm{~g}$ yeast extract per liter of water) by vacuum filtration and dried

88 overnight. The dried chlamydospore mats were ground in a Wiley mill with a \#60 sieve. Zea mays

89 (Silver queen hybrid, Burpee) were grown in plastic cone containers in Metromix soilless medium

90 or in a hydroponic system (Lamdan et al., 2015). The hydroponic system consisted of mason jars

91 (500ml, wide mouth) with a shaker clamp placed inside. The jar was filled to the top of the clamp 
92 ( 220ml) with 0.5x Murashige-Skoog basal medium containing Gamborg’s vitamins and supple-

93 mented with $0.5 \%$ sucrose. The unit was covered with a glass petri dish bottom and autoclaved.

94 Plastic mesh (7 holes/linear inch) previously cut into discs to fit within the jars was autoclaved

95 separately. After sterilization, the mesh discs were placed on top of the clamps, and pregerminated

96 seeds with roots approximately $2 \mathrm{~cm}$ long were threaded through the mesh to contact the growth

97 medium. The glass petri dish bottoms were replaced with sterile plastic petri dish bottoms, as they

98 ensure a tighter fit. All plants were grown under lamps (Sun Blaze T5) with 6500K and 3000K

99 lights at room temperature under a 14:10 light:dark regime.

100

101

102

103

104

105

106

107

108

109

110

111 transcriptomic studies (Taylor et al., unpublished; Malinich et al., 2019). The reads were normal-

112 ized using the TMM algorithm in EdgeR. The normalized reads were then queried for those cor-

113 responding to $h f b 9 a$ and graphed using seaborn and matplotlib packages in python.

\section{Deletion of $h f b 9 a$}


The hfb9a gene was targeted for deletion through homologous recombination using a vec-

116 tor generated via the OSCAR method (Paz et al., 2011) modified for use in T. virens. Primers were

117 designed to amplify approximately $1 \mathrm{~kb}$ of upstream and downstream regions flanking the open

118 reading frame of the gene and contained appropriate Gateway sites for recombination (Supple-

119 mentary Table 1). The flanks amplified from T. virens genomic DNA were purified by adding 90

$120 \mu \mathrm{l}$ of combined PCR product, $270 \mu \mathrm{l}$ TE buffer, and $180 \mu 130 \%$ PEG 8000/30mM $\mathrm{MgCl}_{2}$ to a

121 microfuge tube. This solution was vortexed thoroughly, and then centrifuged for 15 min at maxi-

122 mum speed in the table-top centrifuge. The pellet was resuspended in $15 \mu 1$ of sterile water. A 5

$123 \mu \mathrm{l}$ clonase reaction was performed using $20 \mathrm{ng}$ of combined flanks, $60 \mathrm{ng} \mathrm{pA}-\mathrm{Hyg}$-OSCAR, $60 \mathrm{ng}$

124 pOSCAR, and $1 \mu \mathrm{l}$ of BP clonase (Invitrogen) with incubation in a thermocycler overnight at 25

$125{ }^{\circ} \mathrm{C}$. The reaction was stopped the next morning by adding $0.5 \mu \mathrm{l}$ of proteinase $\mathrm{K}$ and incubating at

$12637^{\circ} \mathrm{C}$ for $10 \mathrm{~min}$. The entire reaction was used to transform E. coli $\mathrm{DH} 5 \alpha$ cells and positive clones

127 were screened as described in Paz et al (2011).

The resulting vector (pHFB9a) was electroporated into A. tumefaciens AGL1 and con-

129 firmed through colony PCR using primers to amplify both flanks and the hygromycin resistance

130 gene (hph) (Supplementary Table 1). Overnight cultures of AGL1 containing the vector were pel-

131 leted and resuspended to an $\mathrm{OD}_{600}$ of 0.15 in induction medium (M9 minimal medium; $100 \mathrm{ml} 5 \mathrm{x}$

132 M9 salts, 3.9g MES, $0.45 \mathrm{~g}$ glucose, $0.25 \mathrm{ml}$ glycerol, to $500 \mathrm{ml}$ with $\mathrm{H} 2 \mathrm{O}$, pH 5.3) with and

133 without $200 \mu \mathrm{M}$ acetosyringone and allowed to incubate for $6 \mathrm{hr}$ at $27^{\circ} \mathrm{C}$. Conidia of T. virens

134 were collected from 4-day old PDA plates, diluted to $5 \times 10^{5}$ conidia/ml, and mixed with bacteria

135 in a 1:1 ratio. Several sterile cellophane squares $\left(\sim 1 \mathrm{~cm}^{2}\right)$ were placed on co-cultivation plates (M9

136 minimal medium with $500 \mu \mathrm{M}$ acetosyringone and $1.5 \%$ agar) and $20 \mu 1$ of the mixed conidia/bac-

137 teria solution were placed on each square. The plates were allowed to incubate for $60 \mathrm{hr}$ before 
138 transferring the cellophane to PDA selection plates containing hygromycin, tetracycline, and chlo-

139 ramphenicol. Positive transformants were transferred to $2 \mathrm{ml}$ PDA slants containing the same an-

140 tibiotics. Once cultures began to sporulate, they were successively transferred to PDA + antibiot-

141 ics, PDA, and back to PDA + antibiotics to ensure stability of the integration. Stable transformants

142 were grown in PDB for 2 days and genomic DNA extracted for PCR analysis. Primers specific to

143 the ORF of the gene and primers outside the 5' flank and inside of hph were used to confirm

144 deletion.

145 Phenotypic analysis of mutants

146 Two mutants and the wild-type were assayed for differences in general morphology and

147 radial growth rate by plating a $3 \mathrm{~mm}$ radius plug of actively growing fungus on four PDA plates

148 each and measured every day for four days. The strains were also tested for differences in myco-

149 parasitic ability in confrontation with $P$. ultimum. Plugs of each fungus were placed on opposite

150 sides of a PDA plate $1 \mathrm{~cm}$ away from the edge of the plate and allowed to grow toward each other

151 for seven days. The length of the growth front of wild-type or mutants was measured from the plug

152 and recorded for comparison. Each experiment was repeated twice with four independent plates

153 per experiment. Biocontrol activity was measured as in Djonović et al. using $R$. solani as the path-

154 ogen rather than P. ultimum (Djonović et al., 2006b). Contact angle measurement was performed

155 as in Crutcher et al. (Crutcher et al., 2015).

156 Oxidative stress assay

157 Oxidative stress tolerance was measured by growth on VMS agar plates containing $10 \mu \mathrm{M}$

158 sodium menadione bisulfite. Agar plugs ( $3 \mathrm{~mm}$ radius) of each strain were placed in the middle of

159 the plates. Radial growth was measured every $24 \mathrm{hr}$ for three days.

160 Root colonization and Induced Systemic Resistance assays 
Maize seedlings were grown in a hydroponic system as described previously. Once the

163 virens strains was placed in the liquid growth medium and gently stirred to distribute. The seed-

164 lings and fungal biomass were incubated for 3 days shaking at $50 \mathrm{rpm}$. The roots were then har-

165 vested and thoroughly rinsed in tap water. The collected roots were ground in liquid nitrogen and

166 genomic DNA was extracted using the same protocol described above. The samples were analyzed

167 via the $\Delta \Delta \mathrm{Ct}$ method of qPCR with actin and phenylalanine ammonia lyase primers to determine

168 the ratio of fungal to maize DNA, respectively (Crutcher et al. 2013). The maize samples were

169 treated as the endogenous control and the WT:Maize DNA ratio was normalized to one relative

170 abundance unit and used as the basis of comparison. Mutants were investigated for changes in ISR

171 activity against the foliar pathogen $C$. graminicola following the protocol of Djonović et al.

172 (Djonović et al., 2007) using Silver Queen hybrid plants instead of the B73 inbred line. The area

173 of individual lesions was measured using ImageJ (Schneider et al., 2012). C. graminicola was

174 utilized due to its status as a top maize pathogen and the consistency of the lesions that it causes.

175 The shoot height of treated plants was measured with a meter stick after removing the plants from

176 the plastic cone containers starting at the seed and ending at the longest leaf tip after straightening.

177 After shoot measurements, the roots of the plants were cleaned under running water to remove

178 attached soil and dried in an oven overnight. The combined dry weight of roots and shoots from

179 each plant was recorded.

180 Confocal microscopy and staining

181 Colonized sections of roots harvested from the hydroponic system after two days incuba-

182 tion with strains of $T$. virens were cleared by treatment with $10 \% \mathrm{KOH}$ for 1 hour at $95 \mathrm{C}$. The

183 samples were equilibrated in PBS ( $\mathrm{pH}$ 7.4) for 1 hour. The equilibrated samples were infiltrated in 
184 a solution of $5 \mathrm{mg} / \mathrm{ml} \mathrm{WGA-Alexa-fluor} 488$ and $10 \mathrm{mg} / \mathrm{ml}$ propidium iodide in PBS (pH 7.4) for

18515 min under vacuum and destained in PBS for an additional $15 \mathrm{~min}$. The stained samples were

186 immediately visualized on an Olympus FV3000 confocal microscope.

187 Enzymatic activity assay of cell wall degrading enzymes

Six replicates of $3 \mathrm{~mm}$ radius plugs of each strain were grown in $2 \mathrm{ml}$ of VMS broth in a

191 total protein concentrations, the absorbance of the samples was measured at $595 \mathrm{~nm}$ and compared

192 to absorbance values of a standard BSA curve. Samples from each well were diluted to a total

193 protein concentration of $10 \mu \mathrm{g} / \mathrm{ml}$. These diluted samples were used for enzyme activity assays.

194 To measure cellulolytic activity, $40 \mu 1$ of each sample were transferred to a well of a 96

195 well microplate and repeated for a total of 3 technical replicates per sample. A $60 \mu 1$ aliquot of 50

$196 \mathrm{mM}$ sodium acetate buffer at a $\mathrm{pH}$ of 4.8 was added to the well along with $10 \mu 1$ of $1 \%$ carbox-

197 ymethyl cellulose. The plate was sealed with adhesive film and incubated in a thermocycler at

$19850^{\circ} \mathrm{C}$ for $60 \mathrm{~min}$. A $50 \mu \mathrm{l}$ aliquot of solution from each well was transferred to a new 96 well plate

199 and $100 \mu \mathrm{l}$ of dinitrosalicylic acid solution was added. The new plate was then incubated at $95^{\circ} \mathrm{C}$

200 for 5 min to allow color to develop, after which $40 \mu \mathrm{l}$ of the developed solution was added to a 96

201 well plate, diluted with $160 \mu 1 \mathrm{H}_{2} \mathrm{O}$, and absorbance measured at 540nm in a microplate reader.

203 plate. To this, $80 \mu \mathrm{l}$ of the same sodium acetate buffer used above and $5 \mu \mathrm{l}$ of $0.5 \mathrm{mg} / \mathrm{ml} \mathrm{4-}$

204 methylumbelliferyl $\beta$-D-N, N', N"-triacetylchitotrioside as a substrate was added. This mixture

205 was incubated for $15 \mathrm{~min}$ at $40^{\circ} \mathrm{C}$, and fluorescence was measured in a microplate reader.

\section{Protein expression and extraction}


Primers were designed to amplify the 423 bp coding sequence from cDNA with $N d e$ I and HindIII restriction sites prepended to the 5' and 3' primers, respectively (Supplementary Table 1). The amplicon and pET30b(+) were double digested with $N d e \mathrm{I}$ and HindIII for 30 min at $37^{\circ} \mathrm{C}$.

210 The digested products were cleaned with a QIAquick PCR cleanup kit (Qiagen, US) and ligated at

211 a 3:1 amplicon:plasmid ratio with t4 DNA ligase (NEB, US) overnight at $16^{\circ} \mathrm{C}$. A $5 \mu$ l aliquot of

212 the ligase mix was transformed into DH5 $\alpha$ competent cells via heat shock. Following a recovery

213 period of one hour in SOC medium, $200 \mu \mathrm{l}$ were plated on an LBA plate containing $50 \mu \mathrm{g} / \mathrm{ml}$

214 kanamycin and incubated overnight at $37^{\circ} \mathrm{C}$. Resulting colonies were screened by PCR for ampli-

215 fication of the ORF of hfb9a and positive colonies were digested with $\mathrm{NdeI}$ and HindIII to deter-

216 mine insert size. Several vectors were then sequenced for confirmation of the correct insertion.

217 The confirmed vector was transformed into E. coli BL21(DE3) competent cells (Invitro-

218 gen, USA) via heat shock. Four resulting colonies were inoculated into $3 \mathrm{ml}$ of LB broth containing

$21950 \mu \mathrm{g} / \mathrm{ml}$ kanamycin. The cultures were shaken at $225 \mathrm{rpm}$ in a $37^{\circ} \mathrm{C}$ incubator until the $\mathrm{OD}_{600}$

220 reached approximately 0.6 (roughly $5 \mathrm{hr}$ ). Expression was induced by adding $0.75 \mathrm{mM}$ IPTG to

221 the cultures with further incubation at $37^{\circ} \mathrm{C}$ for $4 \mathrm{hr}$. The cultures were transferred to $2 \mathrm{ml}$ Eppen-

222 dorf tubes and centrifuged for $5 \mathrm{~min}$ at 4500xg. The resulting pellet was washed with $500 \mu \mathrm{l}$ of

223 phosphate buffered saline (PBS, pH 7), and subsequently resuspended in $500 \mu 1$ of PBS. The cells

224 were lysed by repeated freeze-thaw cycles with liquid nitrogen. A $100 \mu 1$ sample of the solution

225 was collected in a $1.5 \mathrm{ml}$ Eppendorf tube to represent the combined soluble and insoluble fractions

226 of the lysate. The remainder was centrifuged for $5 \mathrm{~min}$ at full speed in a tabletop centrifuge. A 100

$227 \mu$ l sample was taken to represent the soluble fraction of the lysate. Each sample was diluted with

228 gel loading buffer and placed in a boiling water bath for $5 \mathrm{~min} .10 \mu \mathrm{l}$ of each sample were loaded

229 into a $15 \%$ SDS-PAGE gel and run at $35 \mathrm{~mA}$ for 1 hour. 
To assess the presence of the protein of interest, a dot blot was performed using anti-His antibodies conjugated to alkaline phosphatase. For each sample, $3 \mu 1$ of each protein extract and a

232 positive control were dotted onto a nitrocellulose membrane. After drying, the membrane was

233 blocked using 5\% skim milk powder in TTBS for $30 \mathrm{~min}$. The membrane was rinsed briefly with

234 TTBS, and the dilute antibody solution was added and allowed to incubate for 1 hour. The antibody

235 solution was drained off, and the membrane was thoroughly rinsed with TTBS. The membrane

236 was developed by adding $10 \mathrm{ml}$ of BCIP/NBT (Sigma Aldrich, USA) solution to the membrane 237 and incubating for $20 \mathrm{~min}$.

238 An overnight culture of the expressing strain of E. coli was used to start a 2 L culture. The 239 culture was centrifuged for $50 \mathrm{~min}$ at 16,000 rpm with the pellet resuspended in lysis buffer (20 $240 \mathrm{mM}$ Tris $\mathrm{pH} 7.5,100 \mathrm{mM} \mathrm{NaCl}$ ) and $2 \mathrm{M}$ urea. Then $25 \mu \mathrm{l}$ of $1 \mathrm{M} \mathrm{MgCl}_{2}$ and $25 \mu \mathrm{l}$ of DNaseI 241 were added following resuspension, the solution was lysed using a French press, and centrifuged 242 at 16,000 rpm for $50 \mathrm{~min}$ to obtain a pellet. The supernatant was decanted into a separate container 243 for later testing. The pellet was washed twice by resuspending in lysis buffer $+2 \mathrm{M}$ urea and spun 244 at $16000 \mathrm{rpm}$ for $20 \mathrm{~min}$. The final pellet was resuspended in lysis buffer $+8 \mathrm{M}$ urea. The suspen245 sion was spun once more at $16,000 \mathrm{rpm}$ for $20 \mathrm{~min}$. The supernatant containing solubilized inclu246 sion bodies was passed through a HisTrap HP (5 ml column volume, GE, USA) chromatography 247 column using a peristaltic pump. The column was then attached to an FPLC where the bound 248 proteins could be refolded by passing lysis buffer containing a slow gradient (20 column volumes) 249 from $8 \mathrm{M}$ to $0 \mathrm{M}$ urea with $5 \mathrm{mM}$ reduced glutathione and $0.5 \mathrm{mM}$ oxidized glutathione. Following 250 refolding, the protein was eluted by $0-400 \mathrm{mM}$ imidazole gradient. The fractions were analyzed 251 by SDS-PAGE gel, as well as subjected to a dot blot with anti-his antibodies to confirm the pres252 ence of the recombinant protein. 
SM1 production determination

Cultures of each strain were grown in $1 \mathrm{~L} \mathrm{VMS} \mathrm{shaken} \mathrm{at} 150 \mathrm{rpm}$ and $27 \mathrm{C}$ for one week.

255 The cultures were filtered through Whatman \#4 filter paper and the filtrate collected. Proteins were

256 precipitated from the filtrate with ammonium sulfate ( $\sim 8 \%$ saturation) and collected by centrifu-

257 gation. Levels of SM1 production were determined by immunoblotting as in Djonovic et al. 2006a.

258 Arabidopsis MAPK phosphorylation assay

259 Arabidopsis seedlings were grown on plates of 0.5x Murashige-Skoog basal medium with

260 Gamborg's vitamins for ten days. Several seedlings were placed in wells of a 12 well plate with

$261500 \mathrm{ul}$ of sterile water and incubated overnight. The seedlings were then treated with chitin, puri-

262 fied HFB9A, the protein suspension buffer, or purified SM1. The proteins were added to a con-

263 centration of $100 \mathrm{nM}$. After 15 or $30 \mathrm{~min}$, the seedlings were collected, and flash frozen in liquid

264 nitrogen. The frozen seedlings were ground in protein extraction buffer (Li et al., 2015) and run

265 on a 10\% SDS-PAGE gel. The proteins were transferred and blotted with anti-pERK1/2 antibodies

266 and detected by enhanced chemiluminescence.

267 Statistical analysis

268 All data was analyzed for statistical significance using the ANOVA, Tukey's HSD, and/or

269 Kruskal-Wallis functions in R.

$270 \quad$ Results

271 The T. virens genome encodes two canonical type I hydrophobins

272 NCBI PSI-BLAST search using the protein sequence of HFB9A (Genbank Accession:

273 EHK16816.1) revealed a characterized homolog in the T. asperellum genome, TASHYD1. A sec-

274 ond similar hydrophobin was found in the T. virens genome that has not yet been characterized.

275 With MEGA software, a phylogenetic tree was constructed using selected top hits of the NCBI 
276 PSI-BLAST, with HFB9A serving as the query sequence (Figure 1). The tree diverged into two

277 main clades representing proteins that were more similar to HFB9A or HFB3A. The only charac-

278 terized hydrophobin in the phylogeny was TASHYD1, which clustered with HFB9A, indicating

279 that the two proteins may share similar characteristics and roles in the fungus. Additionally, PFAM

280 database scanning revealed a hydrophobin domain with an N-terminal signal peptide and no other

281 conserved domains in the amino acid sequence. The protein sequence of HFB9A was used for

282 homology modeling of protein structure with the I-TASSER software (Yang et al., 2014). The

283 predicted structure of HFB9A (Figure 2) shared structural homology with human defensin and cell

284 adhesion proteins and was predicted to bind a peptide as a ligand. The structure of TASHYD1 was

285 modeled using the same software. Both HFB9A and TASHYD1 successfully model as similar to

286 the solved structure of DEWA from Aspergillus nidulans (Morris et al., 2013) showing the similar

287 core of beta-sheets, with the unique composition of the surface residues most likely responsible

288 for the specific functions.

289 hfb9a is induced during fungal association with maize roots

290 To develop an expression profile for $h f b 9 a$, cDNA generated from RNA of wild-type col-

291 lected at predetermined time points either in the presence of living maize roots $(6,30$, and 54 hpi)

292 or in shaken culture of potato dextrose broth (PDB, collected every day for 7 days) was subjected

293 to RT-PCR. Expression was observed only in samples from the hydroponic system collected $54 \mathrm{hr}$

294 post inoculation, indicating expression of the gene between 30 and 54 hpi (Figure 3A). Expression

295 of the gene from mycelial samples grown in PDB was not detected until 72 hpi but remained

296 constant in the remainder of the samples. In the hydroponic system, attachment of the wild-type

297 and each mutant to the root system of maize seedlings was recorded at approximately 6 hpi, with

298 the entirety of the root system enveloped by fungus at 54 hpi. The initial expression results were 
299 further confirmed by whole transcriptome sequencing data (Figure 3B, 3C, Malinich et al., 2019,

300 Taylor et al. unpublished). In early time points (6-24 hpi, Figure 3B, 3C), the normalized transcript

301 counts are near 0 , while starting at $30 \mathrm{hr}$ post inoculation transcript counts rapidly increase.

302 hfb9a is required for normal hydrophobicity and oxidative stress response

303 The gene encoding HFB9A was deleted via Agrobacterium-mediated transformation with

304 a homologous recombination cassette (Supplementary Figure 1A). The knockouts were confirmed

305 and screened for wild-type copies of the gene by PCR (Supplementary Figure 1B). The $\Delta$ hfb9a

306 mutants demonstrated a statistically significant difference in hyphal surface hydrophobicity as

307 measured by contact angle of a water droplet on the surface of an agar plug ( $\mathrm{p}<0.05$, Figure 4A).

308 There was no significant difference in radial growth on PDA between the mutants and wild-type

309 (Supplementary Figure 2). However, mutant strains grew significantly slower under oxidative

310 stress than wild-type ( $\mathrm{p}<0.05$, Figure 4B). The mutants grew similar as wild-type in confrontation

311 with P. ultimum (Supplementary Figure 3A) and retained biocontrol activity against $R$. solani on

312 cotton roots (Supplementary Figure 3B).

\section{3 hfb9a has a role in host root colonization and induction of systemic resistance}

314 The ability of $\Delta \mathrm{hfb} 9 \mathrm{a}$ mutants to colonize maize roots was significantly reduced in the

315 hydroponic system (Figure 5A). Observations prior to harvest indicated a similar amount of each

316 strain enveloping the roots. Interestingly, upon addition of pregerminated fungal tissue to the hy-

317 droponic medium, individual colonies could be seen attaching to the roots as the biomass became

318 dispersed. This was significantly faster than expected and did not support our initial hypothesis

319 that this hydrophobin was involved in attachment of the fungus to the roots. Additionally, visual-

320 ization of the colonized roots by confocal microscopy indicated attachment to the root epidermis 
321 by the mutant, but only wild-type was able to colonize internal portions of the root sections exten-

322 sively (Figure 5B, 5C).

323 The $\Delta \mathrm{hfb} 9 \mathrm{a}$ mutants were analyzed for their ability to induce systemic resistance against

324 C. graminicola in maize plants. The average lesion area of the plants treated with $\Delta$ hfb9a mutants

325 were significantly larger than the wild-type treated plants, indicating a lack of ISR ( $\mathrm{p}<0.05$, Figure

326 6A, 6B). Plants treated with $\Delta$ hfb9a mutants did not differ significantly in height or dry weight

327 compared to wild-type treated plants (data not shown). Western blot analysis was performed to

328 determine whether the reduction of ISR was due to decreased production of the elicitor protein

329 SM1. Total protein was extracted from wild-type and $\Delta \mathrm{hfb} 9 \mathrm{a}$ strains grown in PDB for $48 \mathrm{hr}$ at

$330150 \mathrm{rpm}$. Each aliquot was diluted to $1 \mathrm{mg} / \mathrm{ml}$ and a western blot performed using anti-SM1 anti-

331 bodies (Djonović et al., 2006a). There was no appreciable difference in the amount of protein

332 detected (Figure 7).

333 hfb9a accelerates $T$. virens cellulase and chitinase activity

334 The $\Delta \mathrm{hfb} 9 \mathrm{a}$ deletion mutants demonstrated approximately $90 \%$ less cellulase activity com-

335 pared to the wild-type fungus (Figure 8A). To determine whether this effect was substrate specific,

336 we duplicated the assay using colloidal chitin, pectin, and lignin. Chitinase activity on colloidal

337 chitin was impacted by the loss of HFB9A ( 95\% reduction, Figure $8 B$ ). However, no impact on

338 pectin or lignin degradation was found with this assay.

339 HFB9A protein complements enzyme activity of mutants

340 The E. coli expression vector pET30B(+) was used to produce recombinant HFB9A with

341 a fused 6xHis tag at the C-terminal end. Expression following induction with IPTG was attempted

342 at $30^{\circ} \mathrm{C}$ overnight or $37^{\circ} \mathrm{C}$ for four hr. Protein production was only detected with cultures incubated

343 at $37^{\circ} \mathrm{C}$ and present only in the insoluble fraction of the lysate. 
The recombinant HFB9A protein was purified from solubilized inclusion bodies by nickel

345 affinity chromatography and refolded on the column. Following elution with imidazole, the frac-

346 tions containing the protein of interest were identified with a dot blot. The positive fractions were

347 pooled, assayed by western blotting (Figure 9), and the protein was stored at $4^{\circ} \mathrm{C}$ for future use.

348 The protein was collected in a buffer with high salt and imidazole. We attempted to exchange the

349 buffer by dialysis but found that the protein aggregated and precipitated out of solution. To avoid

350 aggregation and the resulting insolubility, the protein was rapidly precipitated using 4 volumes of

351 ice-cold acetone; however, the protein remained insoluble upon the reconstitution attempts. The

352 protein was re-solubilized via treatment with formic acid followed by the addition of an equal

353 volume of $30 \% \mathrm{H}_{2} \mathrm{O}_{2}$ to produce performic acid (Wosten et al., 1993). The protein immediately

354 went into solution following evaporation of the acid. The new protein solution retained the same

355 surface activity in comparison with samples dissolved in the original buffer and was used through-

356 out the rest of the study.

The purified protein was able to complement the cellulase activity of the mutants at $1 \mu \mathrm{M}$

concentration. In addition to restoring the enzyme activity of the mutants to wild-type levels, ad-

359 dition of purified protein to the wild-type culture filtrate was able to enhance the cellulolytic ac-

360 tivity against filter paper ( 25\% increase, Figure 10A). The HFB9A protein on its own displays

361 no enzymatic activity and requires culture filtrate to have this effect. The protein buffer was also

362 tested to ensure that there was no interaction in this assay and found no cellulolytic activity. Ad-

363 ditionally, the pure protein at $1 \mu \mathrm{M}$ concentration was able to enhance the activity of commercially

364 sourced cellulase by $13 \%$ compared to the untreated control (Figure 10B).

365 hfb9a induces phosphorylation of AtMAPK 3 and 6 
Purified protein samples of HFB9A and SM1 were applied to Arabidopsis seedlings to determine whether the proteins could induce rapid activation of plant innate immunity commonly associated with microbe associated molecular patterns (MAMPs) by phosphorylation of AtMAPK3 and AtMAPK6. HFB9A treated samples displayed phosphorylation of AtMAPK3 and AtMAPK6 starting 30-min post inoculation, whereas SM1 and buffer control samples did not dis-

371 play phosphorylation 15- or 30-min post inoculation (Figure 11).

\section{Discussion}

Hydrophobins are known to self-assemble at hydrophobic/hydrophilic interfaces. The re-

374 sulting hydrophobin monolayer can modify the properties of the surface to which it adheres. Al-

375 teration of surface properties of materials by hydrophobins enable fungi to interact with previously

376 intractable material as well as adapt to environmental changes. In this study, this phenomenon was

377 demonstrated with HFB9A, as this hydrophobin is required for efficient colonization of maize

378 roots and enhancement of cell wall degrading enzymes activity. Remarkably, ISR in maize treated

379 with $\Delta \mathrm{hfb} 9 \mathrm{a}$ deletion mutant strains was reduced, and in addition to reduced root colonization, one

380 other potential mode of action of HFB9A on ISR may be due to the ability of the purified protein

381 to induce activation of MAP kinase cascade, similarly to other MAMPs such as chitin.

It is not unprecedented that a hydrophobin may act as an elicitor of immunity to influence

383 plant health. HYTLO1 was demonstrated to have a role in induced systemic resistance when ap-

384 plied to leaves, as well as when expressed transgenically in tomato plants (Ruocco et al., 2015).

385 The hydrophobin HFB9A may be functioning in a similar manner as a MAMP. AtMAPK3/6 pro-

386 teins associated with MAMP response and innate immunity were phosphorylated after seedling

387 treatment with purified HFB9A. The phosphorylation cascade starting with AtMAPK3/6 activates

388 WRKY transcription factors involved in plant innate immunity (Adachi et al., 2015). The direct 
activation of these proteins by purified HFB9A suggests that the fungal protein is recognized by the plant as non-self and induces defense responses. This result represents the first direct evidence

391 of MAMP activity by a hydrophobin through induction of MAPK signaling cascades. Another

392 protein with putative MAMP activity from Trichoderma spp. is SWOLLENIN from T. asperellum

393 (Brotman et al., 2008). Brotman et al. suggested that the carbohydrate binding domain of the pro-

394 tein acted as a MAMP, but they did not provide direct evidence, such as MAPK phosphorylation.

395 Additionally, the production of SM1, a known elicitor of ISR, remained unchanged in the mutant

396 strains in the presence of plant roots. However, there was an apparent difference in the dimerization

397 of SM1 between the mutants and wild-type strains. The ability of SM1 to reduce disease progres-

398 sion by $C$. graminicola on maize leaves was shown to be affected by its dimerization state (Vargas

399 et al., 2008). Vargas et al. also hypothesized that glycosylation influenced the ability of SM1 to

400 form dimers. It is tempting to speculate that HFB9a also influences aggregation of SM1, thus al-

401 tering the plant response to the fungus. Remarkably, SM1 application to seedlings did not induce

402 phosphorylation of MAPK proteins. This demonstrates, therefore, that the mechanism by which

403 SM1 and HFB9A induce plant innate immunity is different at the molecular level. Further, it sug-

404 gests that SM1 may not be perceived as a MAMP bu rather may act via as yet unknown mecha-

405 nisms, potentially even as intracellular effector. SM1 and HYTLO1 have both been demonstrated

406 to induce defense responses when applied to foliage (Djonović et al., 2006b, Ruocco et al., 2015).

407 The lack of MAPK activation by SM1 suggests that HYTLO1 may induce defense more similarly

408 to SM1 rather than act as a MAMP as previously hypothesized. The activation of MAPK signaling 409 cascades by HFB9A, paired with decreased ISR as measured by foliar lesion size in plants treated 410 with HFB9a deletion mutant strains, strongly suggests that HFB9A acts as a MAMP. 

manner similar to TASHYD1 (Viterbo and Chet, 2006). However, based on observations of the

413 attachment phenomenon in hydroponics systems and the timing of expression of the gene, this

414 hypothesis is rejected. There is previous evidence that hydrophobins of both classes from T. virens

415 enhance polyethylene terephthalate plastic degradation by cutinases (Przylucka et al., 2014). The

416 enzymatic enhancement of cellulases by HFB9A may aid the fungus in the degradation of plant

417 cell walls, promoting colonization. The demonstrated reduction in cellulase enzyme activity and

418 colonization by the $\Delta \mathrm{hfb} 9 \mathrm{a}$ deletion mutants suggest this may be an additional role for some hy-

419 drophobins. The ability of HFB9A to enhance enzyme activity of cellulases and chitinases, but not

420 other cell wall degrading enzymes such as pectinases may be due to the solubility of the substrates.

421 Cellulose and chitin are both insoluble in water, whereas pectin is highly soluble. We speculate

422 that HFB9A may be aiding the solubility of the substrates that the enzymes are acting upon, pro-

423 moting enzyme attack. Beyond its biological role in the fungus, HFB9A could present a possibility

424 for application in an industrial setting. Fungal hydrophobins are increasingly being used in com-

425 mercial applications, such as in the protection of historic stonework from water damage (Winandy

426 et al., 2019). The cellulase and chitinase enhancement activity of HFB9A makes it a viable candi-

427 date for industrial applications, e.g. as an additive to enzyme cocktails.

Interestingly, the reduction in chitinase activity in $\Delta \mathrm{hfb} 9 \mathrm{a}$ mutants did not influence the

429 ability of the fungus to directly protect against $R$. solani infection of cotton roots, nor mycopara-

430 sitism of $P$. ultimum as measured by confrontation assays. It is possible that the minimal growth

431 medium utilized to express cell wall degrading enzymes may not have been optimal for production

432 of chitinases involved in mycoparasitism. A medium containing colloidal chitin or fungal cell

433 walls might have been more appropriate for the production of mycoparasitism related chitinases. 
434 Additionally, secondary metabolites such as gliotoxin and viridin have been demonstrated to have 435 activity against both $R$. solani and P. ultimum (Howell et al., 1993; Vargas et al., 2014). The low-

436 ered activity of chitinases may be compensated by the activity of the antifungal secondary metab-

437 olites.

438 Overall, we demonstrate that HFB9A has an important role in the interaction between $T$.

439 virens and its host. ISR is significantly reduced when HFB9A is not produced and the protein

440 induces phosphorylation of MAPK proteins involved in immune responses, suggesting that

441 HFB9A may function as a MAMP to activate ISR. Furthermore, the purified protein enhances the

442 cell wall degrading activity of several cell wall degrading enzymes and has potential industrial

443 applications.

\section{Acknowledgements}

445 This work was funded by the Binational Science Foundation (Grant \#2013202) awarded to CMK 446 and BAH and USDA-NIFA (2016-67013-24730) awarded to CMK and MVK.

\section{References}

448 Adachi, H., Nakano, T., Miyagawa, N., Ishihama, N., Yoshioka, M., Katou, Y., et al. (2015)

449 Wrky transcription factors phosphorylated by mapk regulate a plant immune nadph oxidase in

450 nicotiana benthamiana. Plant Cell 27: 2645-2663.

451 Bayry, J., Aimanianda, V., Guijarro, J.I., Sunde, M., and Latgé, J.P. (2012) Hydrophobins-

452 unique fungal proteins. PLoS Pathog 8: e1002700

453 http://dx.plos.org/10.1371/journal.ppat.1002700. Accessed July 29, 2016.

454 Bignell, E. (2012) The Molecular Basis of pH Sensing, Signaling, and Homeostasis in Fungi. In

455 Advances in Applied Microbiology. Academic Press Inc., pp. 1-18.

456 Brotman, Y., Briff, E., Viterbo, A., and Chet, I. (2008) Role of swollenin, an expansin-like 
457 protein from Trichoderma, in plant root colonization. Plant Physiol 147: 779-789

458 http://www.pubmedcentral.nih.gov/articlerender.fcgi?artid=2409044\&tool=pmcentrez\&renderty

459 pe=abstract. Accessed November 13, 2015.

460 Correia, I., Prieto, D., Alonso-Monge, R., Pla, J., and Román, E. (2017) The MAP Kinase

461 Network As the Nervous System of Fungi. Elsevier, .

462 Crutcher, F.K., Moran-Diez, M.E., Ding, S., Liu, J., Horwitz, B.A., Mukherjee, P.K., and

463 Kenerley, C.M. (2015) A paralog of the proteinaceous elicitor SM1 is involved in colonization of

464 maize roots by Trichoderma virens. Fungal Biol 119: 476-486.

465 Djonović, S., Pozo, M.J., Dangott, L.J., Howell, C.R., and Kenerley, C.M. (2006a) Sm1, a

466 proteinaceous elicitor secreted by the biocontrol fungus Trichoderma virens induces plant

467 defense responses and systemic resistance. Mol Plant-Microbe Interact 19: 838-853

468 http://apsjournals.apsnet.org/doi/abs/10.1094/MPMI-19-0838. Accessed August 31, 2016.

469 Djonović, S., Pozo, M.J., and Kenerley, C.M. (2006b) Tvbgn3, a $\beta$-1,6-glucanase from the

470 biocontrol fungus Trichoderma virens, is involved in mycoparasitism and control of Pythium

471 ultimum. Appl Environ Microbiol 72: 7661-7670.

472 Djonović, S., Vargas, W.A., Kolomiets, M. V., Horndeski, M., Wiest, A., and Kenerley, C.M.

473 (2007) A proteinaceous elicitor Sm1 from the beneficial fungus Trichoderma virens is required

474 for induced systemic resistance in Maize. Plant Physiol 145: 875-889

475 http://www.plantphysiol.org/cgi/doi/10.1104/pp.107.103689. Accessed October 4, 2016.

476 Guzmán-Guzmán, P., Alemán-Duarte, M.I., Delaye, L., Herrera-Estrella, A., and Olmedo-

477 Monfil, V. (2017) Identification of effector-like proteins in Trichoderma spp. and role of a

478 hydrophobin in the plant-fungus interaction and mycoparasitism. BMC Genet 18: 16

479 http://www.ncbi.nlm.nih.gov/pubmed/28201981. Accessed September 17, 2018. 
480 Howell, C.R. (1987) Relevance of Mycoparasitism in the Biological Control of Rhizoctonia

481 solani by Gliocladium virens. Phytopathology 77: 992-994.

482 Howell, C.R., Stipanovic, R.D., and Lumsden, R.D. (1993) Antibiotic Production by Strains of

483 Gliocladium virens and its Relation to the Biocontrol of Cotton Seedling Diseases. Biocontrol

484 Sci Technol 3: 435-441 http://www.tandfonline.com/doi/abs/10.1080/09583159309355298.

485 Accessed June 6, 2019.

486 Joensuu, J.J., Conley, A.J., Lienemann, M., Brandle, J.E., Linder, M.B., and Menassa, R. (2010)

487 Hydrophobin fusions for high-level transient protein expression and purification in Nicotiana

488 benthamiana. Plant Physiol 152: 622-33 http://www.ncbi.nlm.nih.gov/pubmed/20018596.

489 Accessed March 31, 2017.

490 Kim, K.T., Jeon, J., Choi, J., Cheong, K., Song, H., Choi, G., et al. (2016) Kingdom-wide

491 analysis of fungal small secreted proteins (SSPs) reveals their potential role in host association.

$492 \quad$ Front Plant Sci 7.

493 Lamdan, N.L., Shalaby, S., Ziv, T., Kenerley, C.M., and Horwitz, B.A. (2015) Secretome of

494 Trichoderma interacting with maize roots: Role in induced systemic resistance. Mol Cell

495 Proteomics 14: 1054-1063 http://www.mcponline.org/content/14/4/1054.abstract?etoc.

496 Li, B., Jiang, S., Yu, X., Cheng, C., Chen, S., Cheng, Y., et al. (2015) Phosphorylation of trihelix

497 transcriptional repressor ASR3 by MAP KINASE4 negatively regulates arabidopsis immunity.

$498 \quad$ Plant Cell 27: 839-856.

499 Malinich, E.A., Wang, K., Mukherjee, P.K., Kolomiets, M., and Kenerley, C.M. (2019)

500 Differential expression analysis of Trichoderma virens RNA reveals a dynamic transcriptome

501 during colonization of Zea mays roots. BMC Genomics 20: 280

502 https://bmcgenomics.biomedcentral.com/articles/10.1186/s12864-019-5651-z. Accessed August 
13, 2019.

504 Morán-Diez, M.E., Trushina, N., Lamdan, N.L., Rosenfelder, L., Mukherjee, P.K., Kenerley,

505 C.M., and Horwitz, B.A. (2015) Host-specific transcriptomic pattern of during interaction with maize or tomato roots. BMC Genomics 16: 8 http://www.ncbi.nlm.nih.gov/pubmed/25608961.

$507 \quad$ Accessed August 31, 2016.

508 Morris, V.K., Kwan, A.H., and Sunde, M. (2013) Analysis of the structure and conformational 509 states of DewA gives insight into the assembly of the fungal hydrophobins. J Mol Biol 425: 244-

510256 https://www.sciencedirect.com/science/article/pii/S0022283612008546?via\%3Dihub.

$511 \quad$ Accessed February 20, 2018.

512 Mustalahti, E., Saloheimo, M., and Joensuu, J.J. (2013) Intracellular protein production in

513 Trichoderma reesei (Hypocrea jecorina) with hydrophobin fusion technology. N Biotechnol 30:

$514262-268$.

515 Paz, Z., García-Pedrajas, M.D., Andrews, D.L., Klosterman, S.J., Baeza-Montañez, L., and Gold, 516 S.E. (2011) One Step Construction of Agrobacterium-Recombination-ready-plasmids (OSCAR), 517 an efficient and robust tool for ATMT based gene deletion construction in fungi. Fungal Genet 518 Biol 48: 677-684.

519 Pieterse, C.M.J., Zamioudis, C., Berendsen, R.L., Weller, D.M., Wees, S.C.M. Van, and Bakker, 520 P.A.H.M. (2014) Induced Systemic Resistance by Beneficial Microbes. Annu Rev Phytopathol $521 \quad$ 52: $347-375$.

522 Przylucka, A., Ribitsch, D., Herrero-Acero, E., Gübitz, G., Kubicek, C.P., and Druzhinina, I.

523 (2014) Hydrophobins class I versus class II: Trichoderma virens HFB9a and HFB9b (class I) are

524 more effective as enhancing agents in enzymatic PET hydrolysis and surface modulators

525 compared to HFB4 and HFB7 (class II). N Biotechnol 31: S190 
https://www.sciencedirect.com/science/article/pii/S1871678414009972?via\%3Dihub. Accessed August 17, 2018.

528 Ramírez-Valdespino, C.A., Casas-Flores, S., and Olmedo-Monfil, V. (2019) Trichoderma as a 529 model to study effector-like molecules. Front Microbiol 10: 1030.

530 Ruocco, M., Lanzuise, S., Lombardi, N., Woo, S.L., Vinale, F., Marra, R., et al. (2015) Multiple

531 Roles and Effects of a Novel Trichoderma Hydrophobin. Mol Plant-Microbe Interact 28: 167532179.

533 Saldajeno, M.G.B., Naznin, H.A., Elsharkawy, M.M., Shimizu, M., and Hyakumachi, M. (2014) 534 Enhanced Resistance of Plants to Disease Using Trichoderma spp. In Biotechnology and Biology 535 of Trichoderma. pp. 477-493.

536 Schneider, C.A., Rasband, W.S., and Eliceiri, K.W. (2012) NIH Image to ImageJ: 25 years of 537 image analysis. Nat Methods 9: 671-675.

538 Seidl-Seiboth, V., Gruber, S., Sezerman, U., Schwecke, T., Albayrak, A., Neuhof, T., et al. 539 (2011) Novel hydrophobins from trichoderma define a new hydrophobin subclass: Protein 540 properties, evolution, regulation and processing. J Mol Evol 72: 339-351

541 http://link.springer.com/10.1007/s00239-011-9438-3. Accessed July 21, 2016.

542 Vargas, W.A., Djonović, S., Sukno, S.A., and Kenerley, C.M. (2008) Dimerization controls the 543 activity of fungal elicitors that trigger systemic resistance in plants. J Biol Chem 283: 1980454419815.

545 Vargas, W.A., Mukherjee, P.K., Laughlin, D., Wiest, A., Moran-Diez, M.E., and Kenerley, C.M. 546 (2014) Role of gliotoxin in the symbiotic and pathogenic interactions of Trichoderma virens.

547 Microbiol (United Kingdom) 160: 2319-2330.

548 Viterbo, A., and Chet, I. (2006) TasHyd1, a new hydrophobin gene from the biocontrol agent 
549 Trichoderma asperellum, is involved in plant root colonization. Mol Plant Pathol 7: 249-258

550 http://doi.wiley.com/10.1111/j.1364-3703.2006.00335.x. Accessed August 2, 2016.

551 Winandy, L., Schlebusch, O., and Fischer, R. (2019) Fungal hydrophobins render stones

552 impermeable for water but keep them permeable for vapor. Sci Rep 9: 6264

553 http://www.nature.com/articles/s41598-019-42705-w. Accessed July 12, 2019.

554 Wösten, H. a (2001) Hydrophobins: multipurpose proteins. Annu Rev Microbiol 55: 625-646.

555 Wosten, H., Vries, O. De, and Wessels, J. (1993) Interfacial Self-Assembly of a Fungal

556 Hydrophobin into a Hydrophobic Rodlet Layer. Plant Cell 5: 1567-1574

557 http://www.ncbi.nlm.nih.gov/pubmed/12271047. Accessed April 3, 2017.

558 Wösten, H.A.B., and Vocht, M.L. De (2000) Hydrophobins, the fungal coat unravelled. Biochim

559 Biophys Acta - Rev Biomembr 1469: 79-86 http://www.ncbi.nlm.nih.gov/pubmed/10998570.

$560 \quad$ Accessed January 12, 2017.

561 Yang, J., Yan, R., Roy, A., Xu, D., Poisson, J., and Zhang, Y. (2014) The I-TASSER suite:

562 Protein structure and function prediction. Nat Methods 12: 7-8

563 http://www.nature.com/articles/nmeth.3213. Accessed April 4, 2018.

564 Zampieri, F., Wösten, H.A.B., and Scholtmeijer, K. (2010) Creating surface properties using a

565 palette of hydrophobins. Materials (Basel) 3: 4607-4625. 
A.

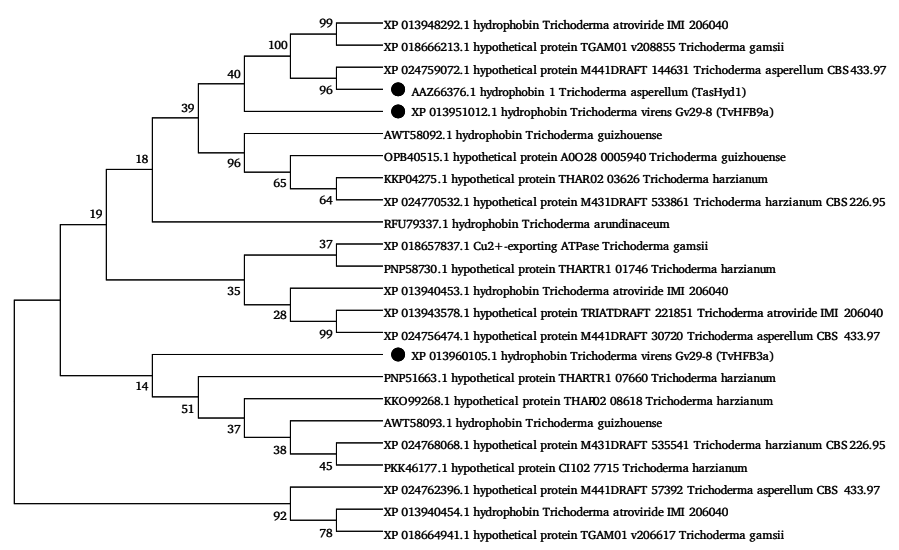

HFB9a clade

B.

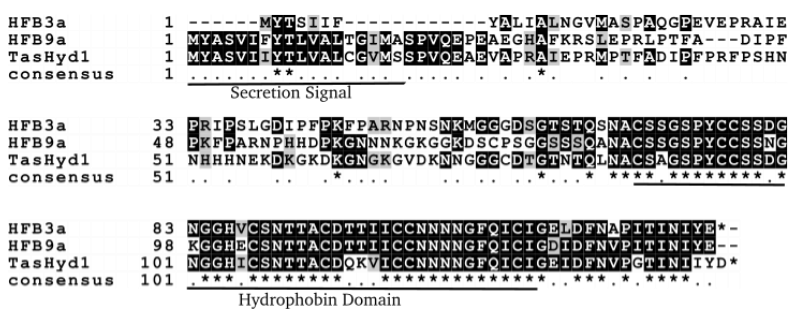

HFB3a clade

569 Figure 1. Phylogenetic comparison of hydrophobins from Trichoderma spp. A. A phylogenetic

570 tree of class I hydrophobins from Trichoderma spp. produced with MEGA software. B. A Clustal-

571 Omega alignment of the amino acid sequences of two T. virens class I hydrophobins (HFB9a and

572 HFB3a) and TASHYD1 from T. asperellum. The residues that make up the N-terminal secretion

573 signal and hydrophobin core are labeled with an underline. Identical residues between all three

574 sequences are labeled with an asterisk. 


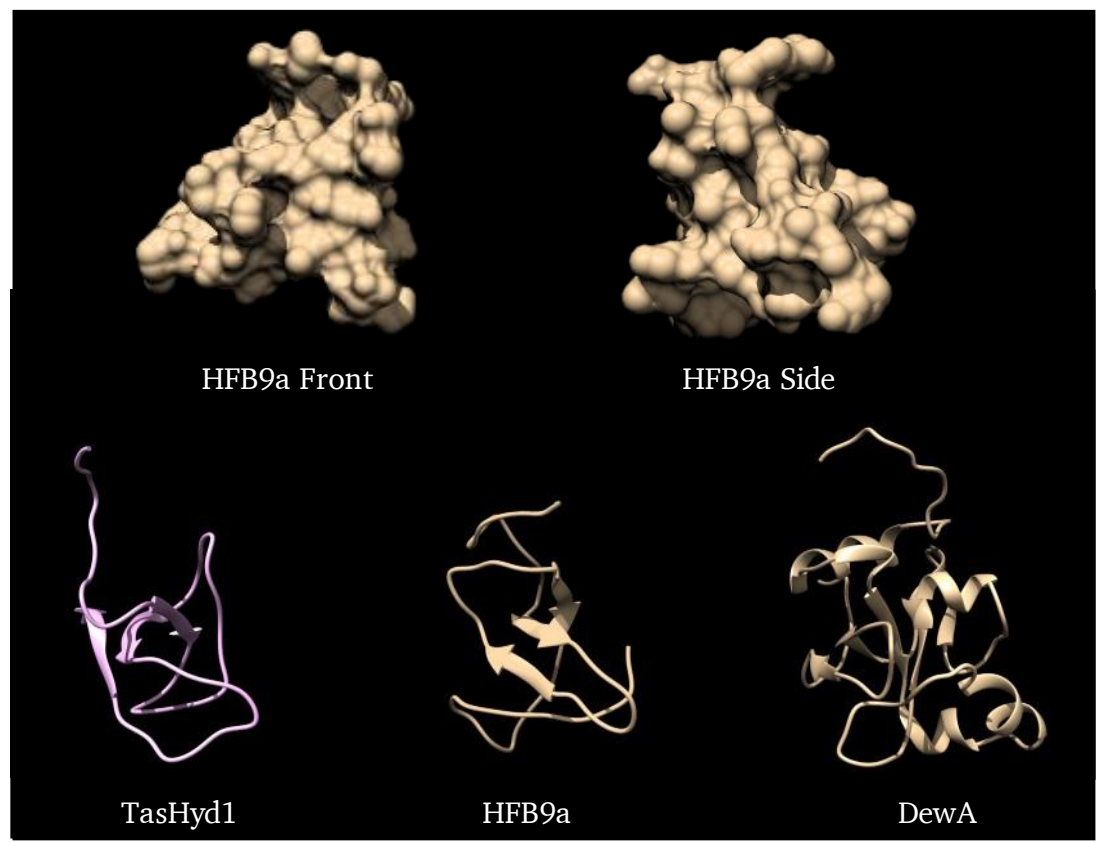

576 Figure 2. A comparison of the predicted protein structures of TASHYD1, HFB9a, and the solved

577 structure of DEWA, a class I hydrophobin from Aspergillus nidulans. Both HFB9A and

578 TASHYD1 successfully model as similar to the solved structure of DEWA from Aspergillus nid-

579 ulans (Morris et al., 2013) showing the similar core of beta-sheets, with the unique composition

580 of the surface residues most likely responsible for the specific functions. 
A.

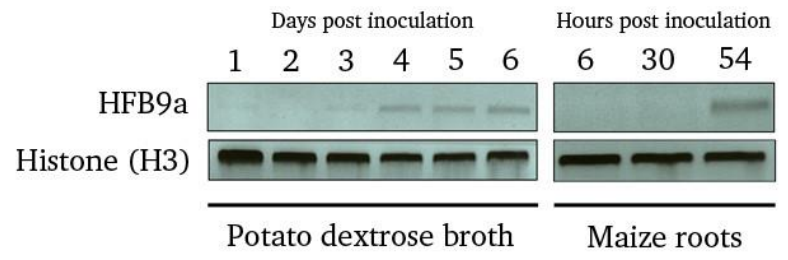

B.

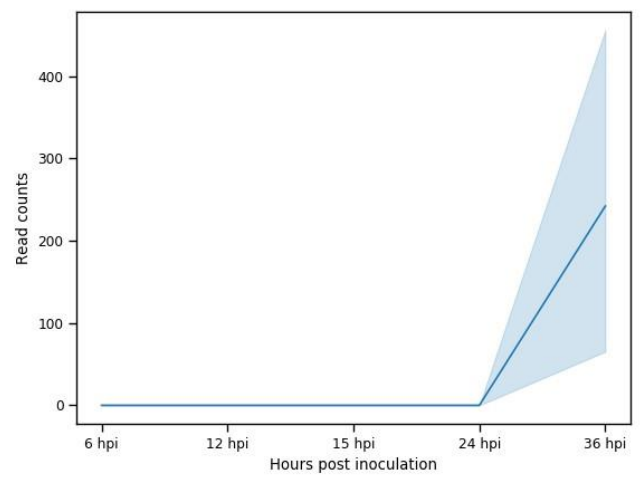

C.

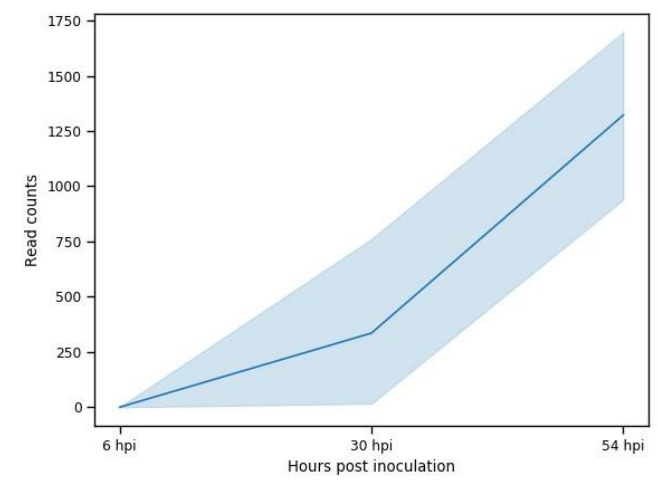

582 Figure 3. Expression profiling of $h f b 9 a$ A. $h f b 9 a$ expression in potato dextrose broth and in the

583 presence of maize roots as measured by RT-PCR. Histone (H3) was used as a loading control. B

584 and C. Normalized read counts from RNA-seq based transcriptomic datasets plotted across time

585 (B: Taylor et al. unpublished, C: Malinich et al., 2019). Raw read counts were obtained from the

586 mentioned studies, then normalized and graphed in EdgeR and Python, respectively. The light

587 colored, shaded regions along the line graph represent the standard deviation at each time point. 
A.
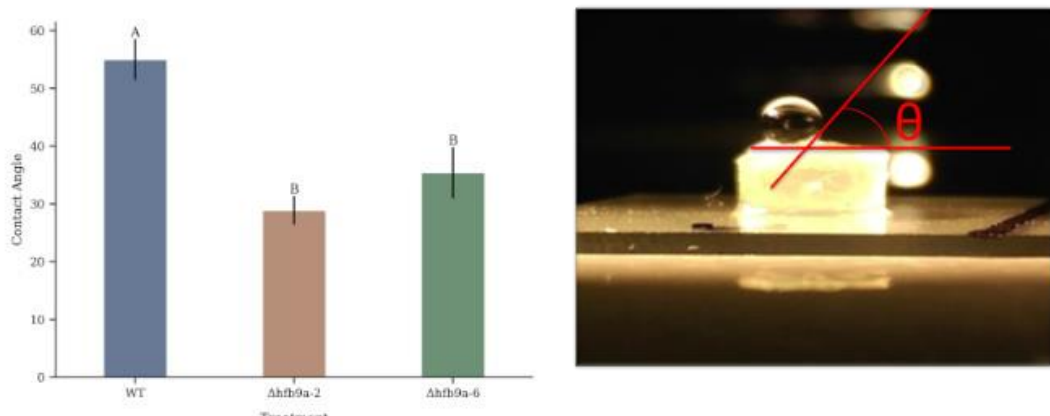

B.

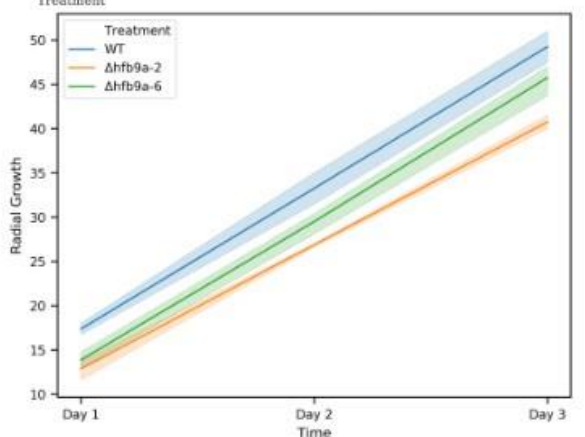

589 Figure 4. Surface hydrophobicity and oxidative stress response. A. Surface hydrophobicity of fun-

590 gal mycelium as measured by contact angle of a water droplet as it lay on the surface of mycelium.

591 Different letters represent statistically different groups $(\mathrm{p}<0.05)$ as determined by ANOVA and

592 Tukey's HSD. Error bars indicate standard deviation. B. Radial growth of each strain over the

593 course of three days on PDA amended with sodium menadione bisulfite to induce oxidative stress.

594 Colored, shaded regions indicate standard deviation. 
A.

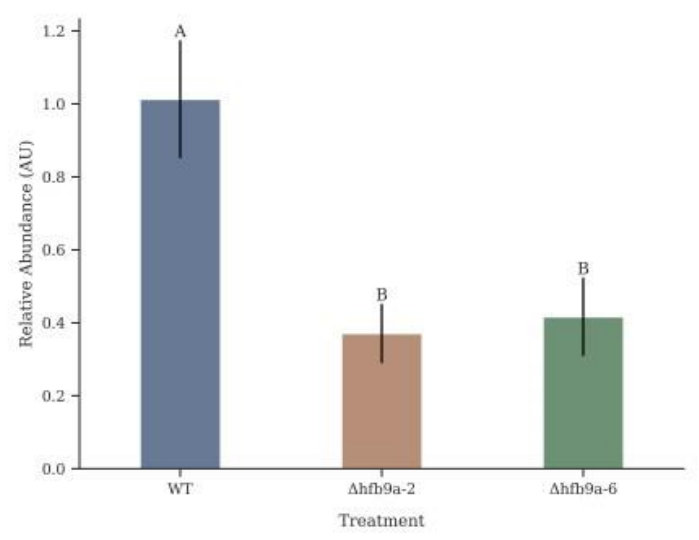

B.

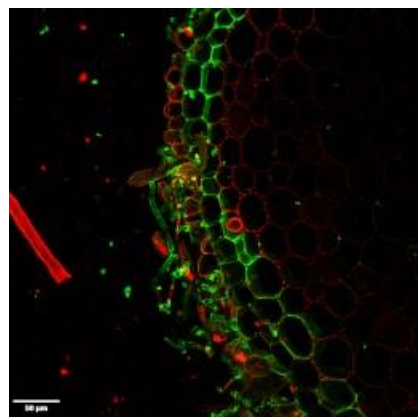

C.

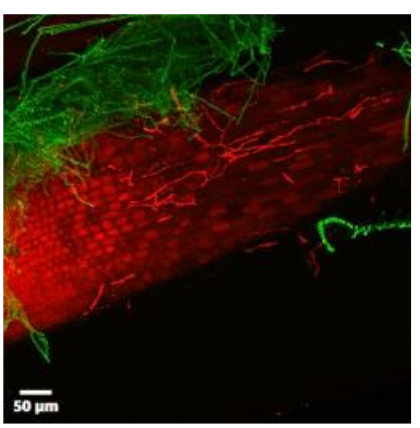

596 Figure 5. Root colonization of maize. A. Root colonization of maize roots in a hydroponic system

597 by different strains of $T$. virens. Quantitative-PCR was used to determine the relative abundance 598 of fungal DNA compared to maize DNA and normalized to the wild-type strain. A smaller number 599 represents less colonization of maize roots by the fungus compared to the wild-type strain. Differ600 ent letters represent statistically different groups $(\mathrm{p}<0.05)$ as determined by ANOVA and Tukey's 601 HSD. Error bars indicate standard deviation. B and C. Confocal micrographs visualizing the wild602 type strain $(\mathbf{B})$ or $\Delta$ hfb9a mutant strain (C) colonizing maize roots. Fungal tissue was stained with 603 WGA-AlexaFluor-488 (green) and maize tissue was stained with propidium iodide (red). Individ604 ual hyphae can be seen in the intercellular spaces of the plant cells colonized by the wild-type 605 strain. In contrast, the only observable hyphae present were extracellularly attached to the surface 606 of roots colonized by $\Delta \mathrm{hfb} 9 \mathrm{a}$ mutant strains. 
A.

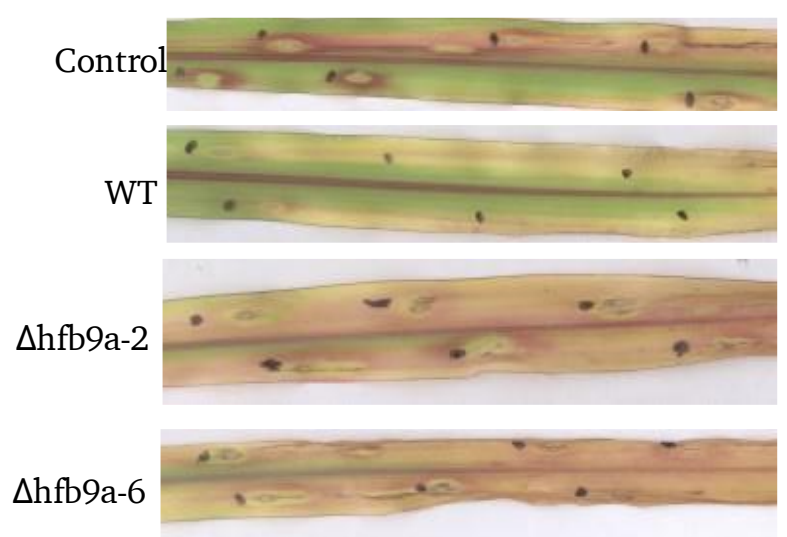

B.

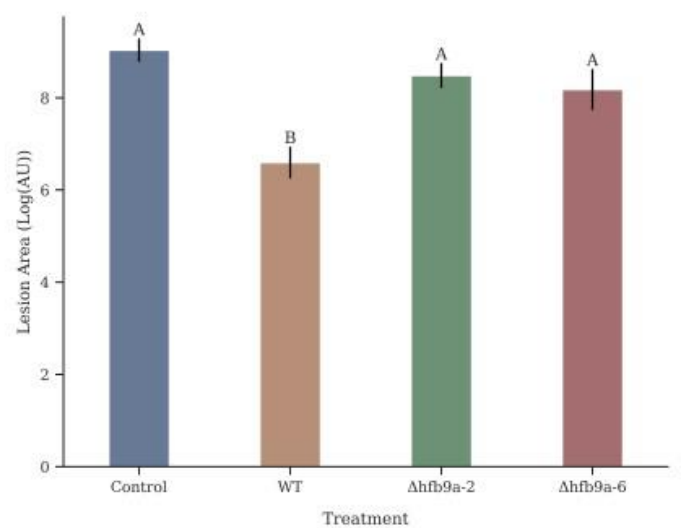

608 Figure 6. Induced systemic resistance of maize plants treated with the wild-type strain or $\Delta \mathrm{hfb} 9 \mathrm{a}$

609 deletion mutants. Areas of individual lesions were measured in ImageJ. Different letters represent

610 statistically different groups $(\mathrm{p}<0.05)$ as determined by ANOVA and Tukey's HSD. Error bars

611 indicate standard deviation. 


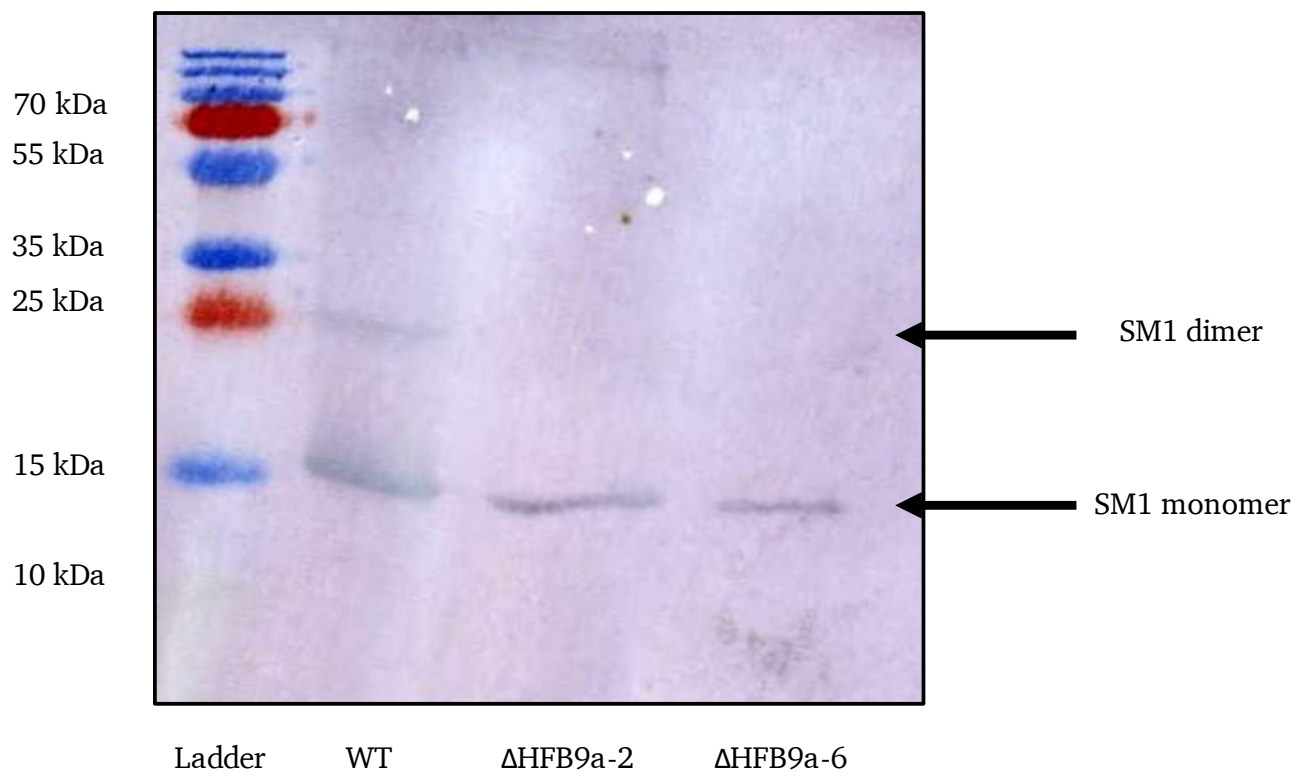

613 Figure 7. SM1 protein production. A western blot using antibodies specific to SM1 to determine

614 the production of SM1 protein by the wild-type strain and deletion mutants $(\Delta \mathrm{hfb} 9 \mathrm{a}-2$ and $\Delta \mathrm{hfb} 9 \mathrm{a}-$

615 6). All lanes were loaded with one ug of protein. There was no discernable difference in production

616 of SM1 between the mutants and wild-type strains. 

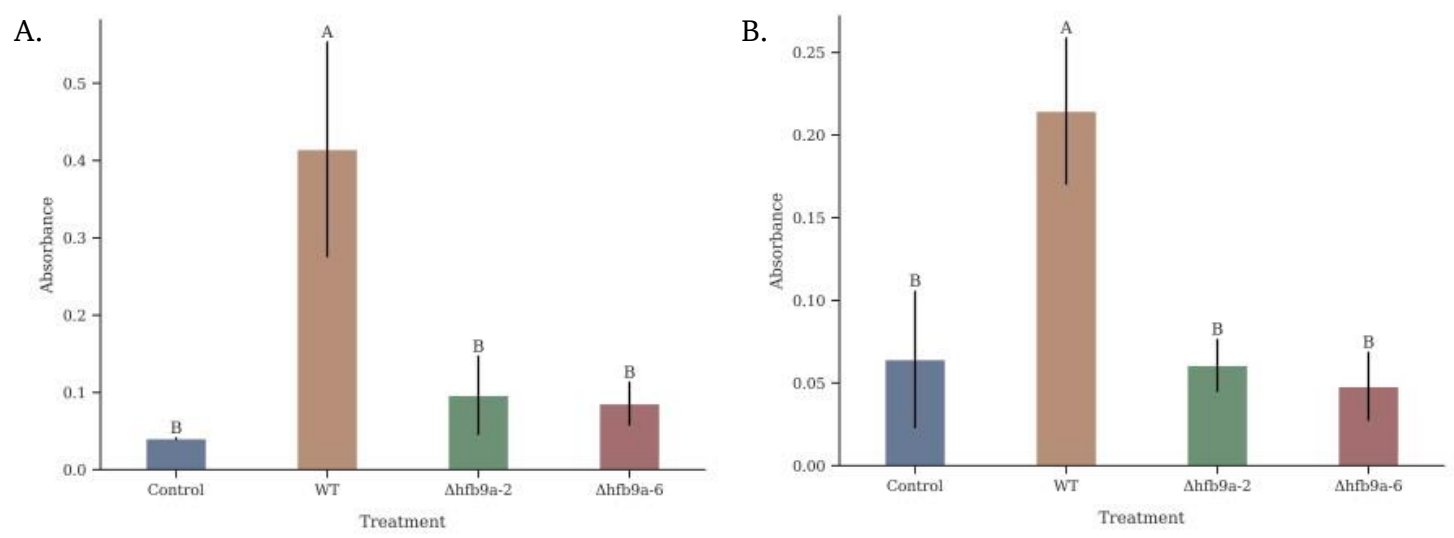

618 Figure 8. Enzyme activity determination. Cellulase (A) or chitinase (B) activity of culture filtrates

619 from the wild-type strain and $\Delta \mathrm{hfb} 9 \mathrm{a}$ deletion mutants as measured by the DNS assay. In each 620 assay, the wild-type strain exhibited significantly higher enzymatic activity on cellulose and col621 loidal chitin (A and B, respectively). Different letters represent statistically different groups ( $\mathrm{p}<$ $6220.05)$ as determined by ANOVA and Tukey's HSD. Error bars indicate standard deviation. 


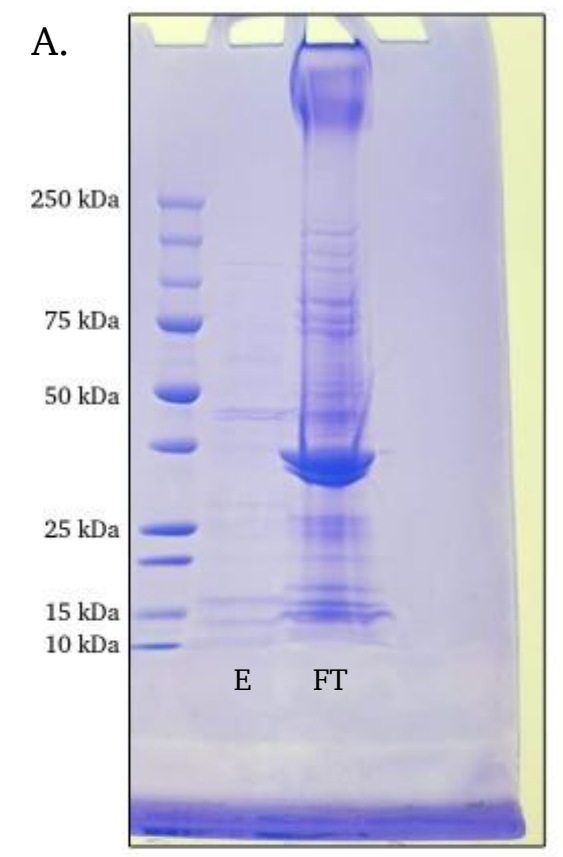

B.

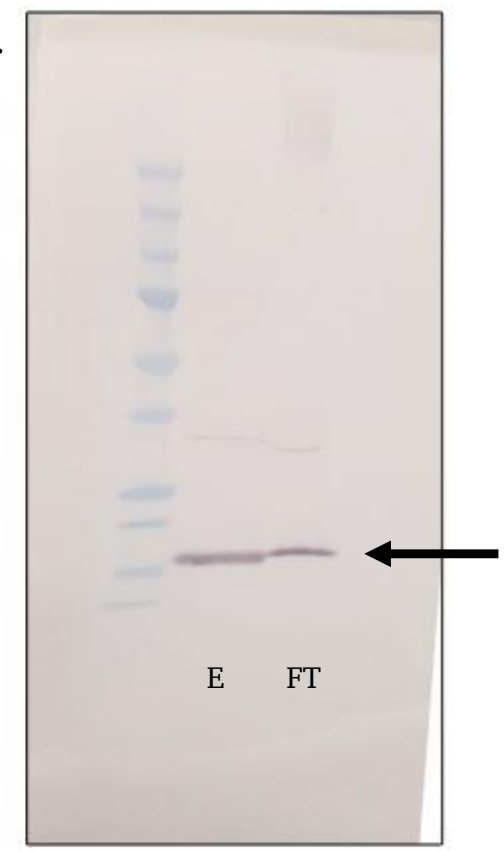

624 Figure 9. Detection of recombinant HFB9A. Coomassie Blue stained SDS-PAGE gel (A) and

625 western blot (B) with antibodies specific to the H6 tag to detect recombinant HFB9A. E: eluted

626 fraction, FT: column flowthrough prior to elution. The arrow indicates the band corresponding to

627 recombinant HFB9A protein. 
A.

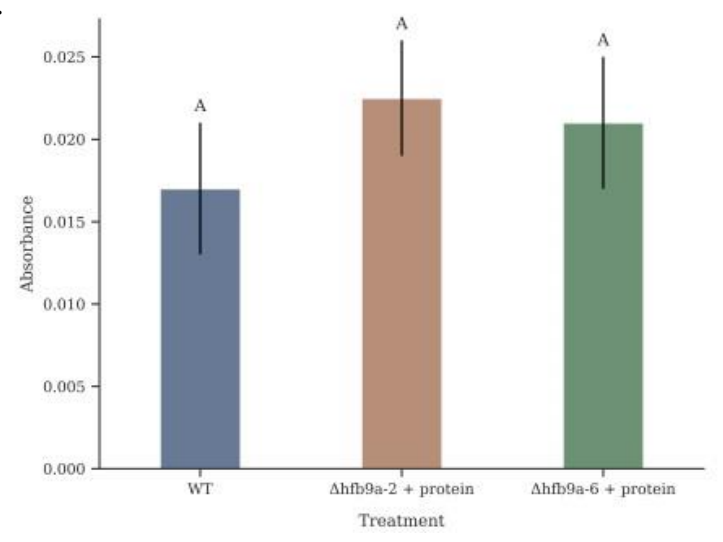

B.

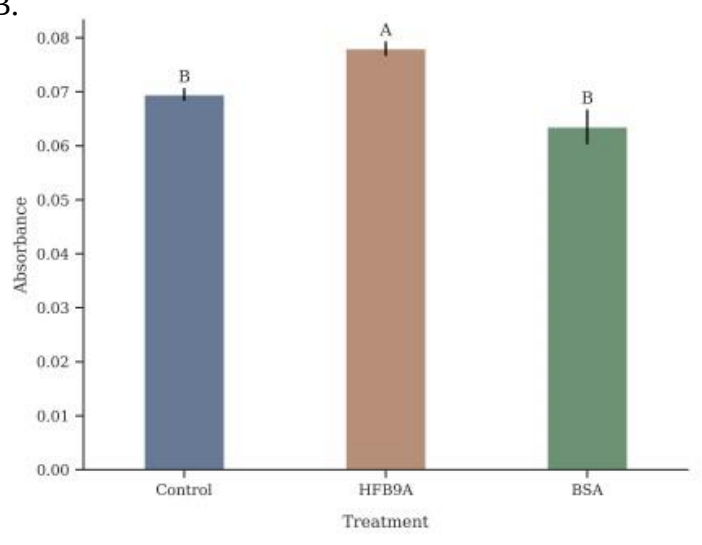

629 Figure 10. Enhancement of enzyme activity by recombinant HFB9A. A. Complementation of

$630 \Delta$ hfb9a deletion mutant cellulase activity by addition of purified HFB9A protein. Cellulase activity

631 was measured by the DNS assay with a cellulose substrate. B. Enhancement of commercial cellu-

632 lase with purified HFB9A protein. BSA treatment was included as a control at the same molar

633 concentration as HFB9A. Different letters represent statistically different groups $(\mathrm{p}<0.05)$ as de-

634 termined by ANOVA and Tukey's HSD. Error bars indicate standard deviation. 


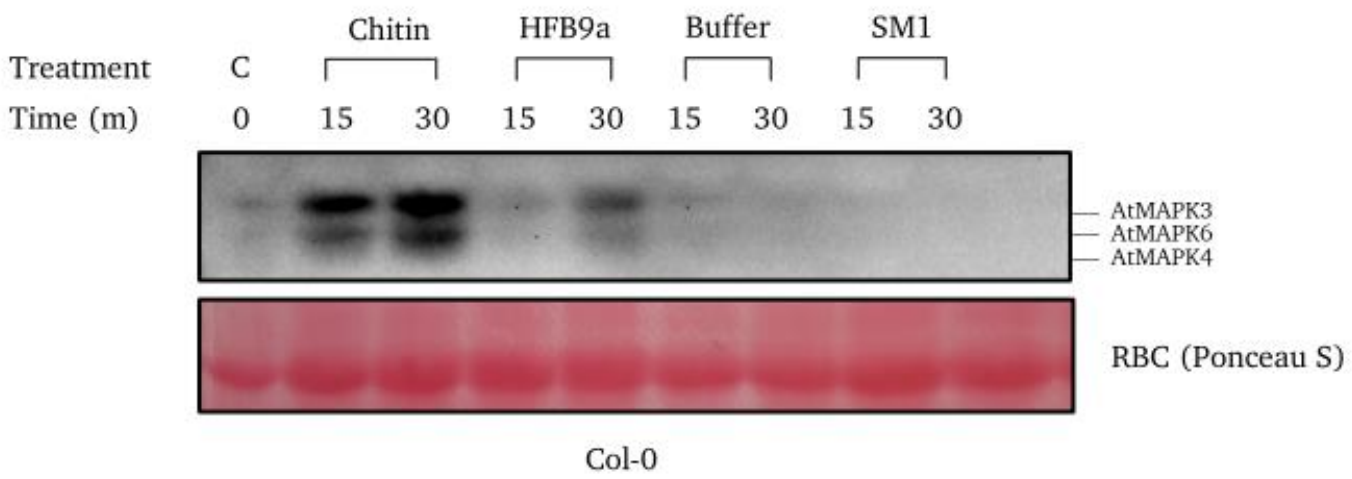

636 Figure 11. MAMP recognition by Arabidopsis thaliana. MAPK phosphorylation of Arabidopsis

637 by addition of HFB9A over the course of 15- and 30-min. Phosphorylation was detected by anti638 bodies specific to pERK1/2. Chitin was included as a positive control. 